\title{
Future Direction for Next Generation Web
}

\author{
http://dx.doi.org/10.3991/ijet.v8i6.2916 \\ Young B. Choi ${ }^{1}$, Young Han $\mathrm{Choe}^{2}$ and Tae H. Oh${ }^{3}$ \\ ${ }^{1}$ Regent University, Virginia Beach, USA \\ ${ }^{2}$ ITU-T, Geneva, Switzerland \\ ${ }^{3}$ Rochester Institute of Technology, Rochester, USA
}

\begin{abstract}
We explore recent developments on the Web and forecast future development trends of Next Generation Web. This is based upon the current technologies and emerging Web technologies developed by international standard organizations. The changing requirements of Web users and industry market will be introduced.
\end{abstract}

Index Terms-Next Generation Web, World Wide Web, Web OS, Standardization

\section{INTRODUCTION}

The Internet is called the "network of networks." It links millions of people around the world, each of whom is using a computer connected to a smaller network such as the one in their office, or school, or to a commercial network. The World Wide Web (WWW) is a system of interlinked hypertext documents accessed via the Internet. With a web browser, one can view web pages that may contain text, images, videos, and other multimedia.

As the Internet has become an essential tool in our daily lives, the World Wide Web is being used as the most important utility. We can use to access various resources distributed over the Internet. Recent wireless and mobile trends of the Internet are also accelerating development of its customized Web services according to diverse users' requirements.

The users are in need of more powerful and customized Web services with fortified privacy and security control capabilities. Also, users are requesting more individualized Web services and many users are influenced by the past experience of the services.

There is an increasing demand for Web users that want fast access time to their target Web services with vendorneutral Web browser with a language such as HTML5. Platform-independency reduces the use of proprietary plug-in-based Rich Internet Applications (RIAs) such as Microsoft Silverlight, Sun JavaFX, Illustrator, PhotoShop and Adobe Flash although it will take time to satisfy demanding requirements of the Web users.

\section{NEXT GENERATION WEB}

Next Generation Web can be defined as future Web with enhanced current Web features plus other emerging features. As the Internet usage has been changing with better broadband Internet access and wireless communications using various mobile communication devices with converging capabilities of various multimedia services, the shape of future Web, i.e., Next Generation Web can be figured out as a meaningful Internet usage tool. Recently, Internet Corporation for Assigned Names and Number (ICANN) announced the introduction of non-Latin script domain names [6] and it would be one of the biggest changes in its début of the Internet in 1969. This will enable more users of the Internet to use the Web friendly than before and the Internet usage will continue to be more active than before. New Web services such as Google Wave were introduced [4]. Google Wave is a kind of convergence Web-based e-mail service integrating communication, collaboration, and file sharing services that are available in the market. New interesting features of the Next Generation Web will be developed depending upon the users' requirements generated in using those new Web services in their daily activities $[10,12]$.

Over the Internet, the users started to use the Web conveniently to execute their common business application programs online since 2006. These programs are accessible from any Web browser over the Internet even if the distributive software and data are stored on servers over the Internet without the users' knowledge about their locations, expertise, or control over the technology infrastructure in the "cloud" that supports them [11, 16]. Cloud computing makes the users storing files and software remotely in cloud instead of storing them on a hard drive or server at their offices. A few examples of cloud computing are Web-based e-mail like Gmail and Hotmail, communication tools like Skype, video sites like YouTube and Vimeo and music-sharing sites such as SoundCloud. Since 2008, global IT enterprises such as Amazon, Google, and salesforce.com started to deliver following services:

- Infrastructure as a Service (IaaS) delivering computer infrastructure typically a platform virtualization as a service

- Platform as a Service (PaaS) delivering a computing platform and solution stack as a service

- Software as a Service (SaaS) [13] delivering a software application license to customers for use as a service on demand.

However, cloud computing also has its own issues such as security, reliability, availability, and interoperability issues to satisfy the users' demands in full.

\section{CURRENT MAJOR TECHNOLOGIES FOR NEXT GENERATION WEB}

There are five outstanding major technologies for Next Generation Web in the market as a following list.

1. Emerging markup languages - HTML5

2. Mobile web $[15,25]$

3. Social Web

4. Structure data

5. Real-time Web

To satisfy the diverse and ever increasing Web users' dynamic requirements, Web applications for client interoperability, W3C develop following features and webs [23].

- Mobile Web to better support the mobile device usage environment 
- Voice standards to support verbal communications

- Web Services to deliver diverse services in a distributed environment

- Semantic Web standard to support intelligent service processing

- Privacy/Web security standards.

Overall, the Web is continuously evolving towards the Next Generation with three major elements: Web Services, Semantic Web, and Ubiquitous Web [22].

As one of the possible set of component technologies of Next Generation Web, there are five major component technologies such as Ubiquitous Web, Mobile Web, Web 2.0 [5, 8, 9, and 21], Web Platform [14], and Web Accessibility.

Ubiquitous Web Technologies make possible different types of devices including desktops, office automation devices, home appliances, mobile phones, ubiquitous devices such as sensors and effectors to communicate each other seamlessly via the Web. Mobile Web Technologies make it possible for diverse types of mobile devices including cell phones, Personal Digital Assistants (PDAs) to exchange Universal Resource Indicator (URI) based resources via Hyper Text Transfer Protocol (HTTP) and use markup languages such as Extended Markup Language (XML). Web 2.0 technologies make it possible to use a more 'distributed and open' Web as a Platform by enhancing the capabilities of existing Web applications and service environments. Web as a Platform Technologies make it possible for users to link and execute local or remote applications, services, and data by using the various currently available standardized Web technologies. Web Accessibility Technologies, including cursor-based browsing, adaptive zoom, Accessible Rich Internet Application (ARIA) markup support make it possible the Web users primarily for disabled uses, but for all user agents including highly limited devices such as mobile phones to access Web content. A series of Web content access guidelines were published by $\mathrm{W} 3 \mathrm{C}$ as the document WCAG (Web Content Accessibility Guidelines) [23].

The Web is also migrating toward Social Web which is used for people socialize via WWW. People are brought together by people oriented Websites such as Facebook and MySpace or by common hobby oriented Websites such as Flickr and Kodak Gallery. There are many Webbased Collaboration Tools available in the market [1]. Although there are paid or subscription services such as Basecamp and Zimbra, there are many alternatives providing free and similar, if not better, features including MS Live docs, Google Docs and bubbl.us. The functions of those tools are very diverse ranging from basic brainstorming or white boarding to fully-featured project management applications.

\section{EMERGING TECHNOLOGY TRENDS}

The major technologies for a Next Generation Web discussed in section 3 are interacting with many emerging technologies having enhancing functionalities to deliver better services to users. These include technologies such as telematics/LBS, broadband convergence service, Digital Mobile Broadcasting (DMB)/TDVision (TDV), home service, Radio Frequency Identification (RFID)/User Sensor Network (USN) service, IT service, next generation mobile communication service, intelligent robot, embed- ded software/terminal and digital contents/software solution [14].

Beyond the technologies mentioned above, there are many other technologies to consider. One of them is Web development tools. Up to now, currently used widget tools are mainly used to create User Interfaces (UIs). They are not the Web applications that general Web developers want. Canvas, which is a Hyper Text Markup Language (HTML) extension for procedural graphics allowing dynamic scriptable rendering of bitmap images and What You See Is What You Get (WYSIWYG), is used to describe a system that make displayed content during editing looks very similar to the final output such as Web page, slide presentation, or a printed document. In case of Canvas, it is an important tool in Web development since the program offers a more compact way to represent images. Tools which can offer these features will be useful to satisfy the Web developers' requirements and further stimulate the use of HTML5.

Currently, different Web browsers support different chipsets and drivers. Fennec, which is the build of the Mozilla Firefox Web browser for smaller non-PC devices, mobile phones and PDA, is UNIX based. Maemo is a software platform developed by Nokia for smart phones and the Internet Tablets based on the Debian OS. Maemo based on Debian GNU/Linux supports hardware acceleration at Maemo platform. OpenGL ES (OpenGL for Embedded Systems), which is a subset of the OpenGL 3D graphics API, designed for embedded devices like mobile phones, PDAs, and video game consoles and Canvas use vector engines for processing respectively.

Accessing the resources in cloud computing environment over the Internet using mobile or fixed hardware devices will provide the challenge in realizing a standardized solution for a seamless Web access for the users to achieve their goal of enjoying Web services without disruptions.

In this respect, major Web browser vendors including Microsoft, Mozilla, Opera software, and Apple are striving to embed emerging technical features into the Web market according to the users' new requirements into their Web browsers such as Internet Explorer, Firefox, Opera, and Safari respectively in developing their products.

Another emerging issue in the Web market is Web OS. HP webOS is a mobile operating system based on a Linux kernel, initially developed by Palm, which was later acquired by Hewlett-Packard. The official name is webOS, uncapitalised, but $W e b O S$ is also used. One example is a Web browser Gazelle introduced by Microsoft in February 2009 [7]. It acts like as multi-purpose Operating Systems with browser kernel exclusively protecting all system resources and sharing across Web sites. On the other hand, Google Chrome OS is running Web applications on the Google Linux-based kernel. It is a light weight OS devoted to use the Web and was announced on 7 July, 2009. We can consider Google Chrome OS as a combination of Linux kernel and Google Chrome Web browser, and Gazelle OS is a combination of Windows kernel and Internet Explorer. It is expected that a miniaturized OS kernel which can drive a Web browser (not heavy/full desktop OS kernels such as XP, Vista, and Windows 7 which was released in October 2009 in the market), Web components, and various plug-ins are being developed by Microsoft now. Considering current development trends 
of Web browser and Web OS, various development directives of different vendors will converge to development effort based on standardized technical specifications of Web browser and OS accepted by the industry for higher interoperability of diverse Web user applications.

Web OS is also being developed toward Mobile Web OS such as Palm Web-OS running on a Linux-based kernel with proprietary components developed by Palm to satisfy increasing requirements of mobile wireless Web users. The Palm Pre smart-phone is the first device to launch with Web-OS and Palm Pre and Web-OS were released on June 6, 2009.

\section{FUTURE DEVELOPMENT DIRECTION OF NEXT GENERATION WEB TECHNOLOGIES}

The following list of standard organization organizations (SDOs) have been working on the emerging technologies of Next Generation Web.

- Consumer Electronics Linux Forum (CELF)

- Digital Video Broadcasting Project (DVB)

- Electronic Product Code (EPC)

- Institute of Electrical \& Electronics Engineers, Inc. (IEEE)

- International Organization for Standardization (ISO)

- International Telecommunication Union (ITU)

- Java Community Process (JCP)

- Moving Pictures Expert Group (MPEG)

- Open Geospatial Consortium (OGC)

- Open Mobile Alliance (OMA)

- Object Management Group (OMG)

- World Wide Web Consortium (W3C)

- $3^{\text {rd }}$ Generation Partnership Object (3GPP)
Table 1 shows a mapping between emerging technologies relevant to a Next Generation Web and SDOs involved in Next Generation Web technologies compiled based on referencing various resources including [14]. The mark ' $\mathrm{X}$ ' in the table shows that a given SDO is involved in developing respective set of emerging technologies relevant to the Next Generation Web. For example, ITU-T is involved in development of standards for emerging technologies relevant to the Next Generation Web such as broadband convergence service, DMB/TDV, home service such as residential technology [20], RFID/USN service, next generation mobile communication service, and intelligent robot technologies.

As we can see in Table 1, five standard organizations are involved in intelligent robot technologies and four in digital contents/software solution technologies. Also, three standard organizations are involved in DMB/TDV technologies, RFID/USN service technologies, and next generation mobile communication service technologies respectively.

This analysis shows that Next Generation Web will develop mainly based on those technologies considering the market growth direction of the current Web market. Besides those technologies, there are many other factors we need to consider in future development of Next Generation web technologies. As discussed in section 3, HTML5 is being developed with emerging features such as Cascading Style Sheets (CSS3), RIA, and Mobile Web. Its impact on the Web industry will be significant. The other issue is whether it is possible and desirable to replace Operating Systems with Next Generation Web.

In considering all of these issues in various applications of Next Generation Web, using interoperable standardized technologies would be extremely useful for seamless fixed

TABLE I.

A MAPPING BETWEen EMERGING TECHNOLOGIES RELEVANT to NEXT GENERATION WEB AND STANDARD ORGANIZATIONS INVOLVED IN NEXT GENERATION WEB TECHNOLOGIES

\begin{tabular}{|c|c|c|c|c|c|c|c|c|c|c|c|c|c|c|c|}
\hline $\begin{array}{l}\text { Standard Organi- } \\
\text { zations/ Emerging } \\
\text { Technologies }\end{array}$ & $\underset{\mathbf{F}}{\text { CEL }}$ & DVB & EPC & IEC & $\begin{array}{c}\text { IEE } \\
\mathbf{E}\end{array}$ & ISO & ITU & JCP & $\begin{array}{c}\text { MPE } \\
\text { G }\end{array}$ & $\begin{array}{c}\text { OG } \\
\text { C }\end{array}$ & $\underset{\mathbf{O M}}{\mathbf{A}}$ & OMG & W3C & $\stackrel{\text { 3GP }}{\mathbf{P}}$ & $\begin{array}{c}\text { Number } \\
\text { of Stand- } \\
\text { ard Organ- } \\
\text { izations } \\
\text { Involved }\end{array}$ \\
\hline Telematics/LBS & & & & & & $\mathrm{X}$ & X & & & X & X & & & & 4 \\
\hline $\begin{array}{l}\text { Broadband conver- } \\
\text { gence service }\end{array}$ & & & & & & & $\mathrm{X}$ & & & & & & & & 1 \\
\hline DMB/TDV & & $\mathrm{X}$ & & & & & $\mathrm{X}$ & & $\mathrm{X}$ & & & & & & 3 \\
\hline Home service & & & & & & & $\mathrm{X}$ & & & $X$ & & & & & 2 \\
\hline RFID/USN service & & & $X$ & & & $X$ & $\mathrm{X}$ & & & & & & & & 3 \\
\hline IT service & & & & & & $\mathrm{X}$ & & & & & & & & & 1 \\
\hline $\begin{array}{l}\text { Next generation } \\
\text { mobile communica- } \\
\text { tion service }\end{array}$ & & & & & & $X$ & $X$ & & & & & & & $X$ & 3 \\
\hline Intelligent robot & & & & $X$ & $\mathrm{X}$ & $\mathrm{X}$ & $\mathrm{X}$ & & & & & $\mathrm{X}$ & & & 5 \\
\hline $\begin{array}{l}\text { Embedded soft- } \\
\text { ware/terminal }\end{array}$ & $X$ & & & & & & & $X$ & & & & & & & 2 \\
\hline $\begin{array}{l}\text { Digital con- } \\
\text { tents/software solu- } \\
\text { tion }\end{array}$ & & & & & & X & & & $X$ & & $\mathrm{X}$ & & X & & 4 \\
\hline
\end{tabular}




\section{SPECIAL FOCUS PAPER \\ FUTURE DiRECTION FOR NEXT GENERATION WEB}

and mobile Web services delivery over the Internet. In that sense, the following recent Web technology standard issues of $\mathrm{W} 3 \mathrm{C}$ show some clues to the future direction of Next Generation Web [23]:

1. Device API standards for Mobile Web device control

2. Video Web standards toward common metadata for diverse Web-based video services

3. Mobile Web standards for seamless Web services access using diverse Mobile Web devices

4. RIA standards for Web applications for including widgets

5. HTML5 standards toward comprehensive Web markup specification

6. Social Web standards Web-based social services using Semantic Web technologies.

The following Figure 1 shows major decision factors influencing future development direction of Next Generation Web.

As you can see in Figure 1, major decision factors will influence in the development directions of Next Generation Web technologies including Web browsers, languages, OSs, and development tools. At the same time, emerging technologies with enhancing functionalities to deliver better Web services to users such as telematics/LBS, broadband convergence service, DMB/TDV, home service, RFID/USN service, IT service, next generation mobile communication service, intelligent robot, embedded software/terminal and digital contents/software solution will influence the development direction of Next Generation Web. Those solutions will interact with major Next Generation Web technologies to satisfy users' more diverse and dynamic requirements in a sustainable manner.

\section{CONCLUSION}

In this paper, we identified current major technical components of Next Generation Web and its emerging technologies based on the standardization activities of major international organizations relevant to emerging Next Generation Web technologies, leading Web software and software vendors, users' increasing requirements, and the Web market.

We need to analyze diverse Web users' new application requirements in depth in figuring out what would be the Next Generation Web. Although many interesting technologies for Next Generation Web are available in the market, only demanding and popular requirements of the users will survive in the market in the long run and play an important role in shaping the future configuration of Next Generation Web as you can see the changing trend of the users' requirements [2].

To access the Web over the Internet seamlessly, a Web user will want to use desktop or any mobile device of choice with universal Web engine and browser having features of user friendly accessibility, fortified security, and diverse functions with globally interoperable standards. To make all of these possible, we may think of development of standardized Web OS like Linux in software development industry as one of the possible choices o future Next Generation Web development for interoperability.

A standardized Web OS is another issue in the Next Generation Web. The current Web relevant software, hardware, and service standards including HTML5, Device API, Video Web, Mobile Web, RIA, and Social Web will interact with emerging technologies based on diverse requirements of the Web users and the growth of Web market according to the users' changing usage trends of Web services. The eventual future topology of the Next Generation Web will be significantly influenced and decided by the users' diverse Web service requirements, current and emerging Web technologies, industry's business models to generate revenue, and international Web technology standard development directions and progress.

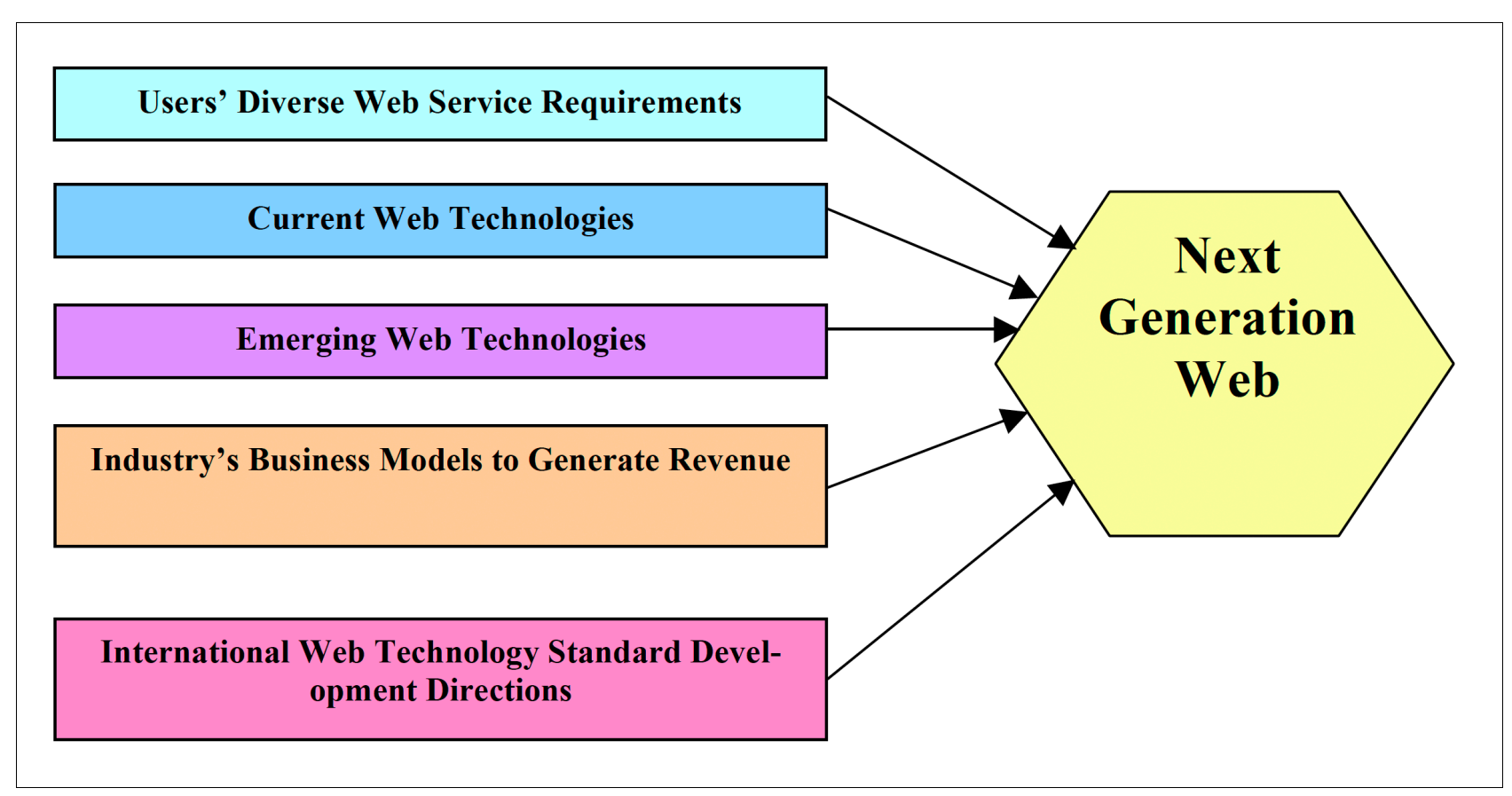

Figure 1. Major Decision Factors Influencing Future Development Direction of Next Generation Web 


\section{SPECIAL FOCUS PAPER \\ Future DiRECTION FOR NEXT GENERATION WEB}

\section{REFERENCES}

[1] 15 Free Tools for Web-based Collaboration, $\mathrm{URL}=\mathrm{http}: / /$ sixrevisions.com/tools/15-free-tools-for-web-basedcollaboration/.

[2] 50 Best Websites 2009, URL $=$ http://www.time.com/time/ specials/packages/article/0,28804,1918031 1918016,00.html

[3] Google Chrome OS, URL=http://en.wikipedia.org/wiki/ Google Chrome OS.

[4] Google Wave: What's All the Fuss About? URL= http://www.time.com/time/magazine/article/0,9171,1929231,00.ht $\underline{\mathrm{ml}}$

[5] H. J. Lim and J. K. Park, Emerging Issue Report 10, Korea Institute of Science and Technology Information, ISBN 978-89-6211086-9 98570 .

[6] Internet set for big change with introduction of non-Latin script domain names, Yahoo! News Canada, $\mathrm{URL}=$ http://ca.news.yahoo.com/s/capress/091026/business/as_tec internet_names_1

[7] Introducing Microsoft's Gazelle: A Web Browser as a MultiPrincipal OS, URL $=$ http://www.readwriteweb.com/archives/ introducing_microsofts_gazelle.php

[8] J. H. Jeon and S. Y. Lee, The Trends of Mobile Web 2.0 and Mobile Standardization ETRI Technology Trends Analysis, Vol. 22, No. 6, pp. 84-95, December 2007.

[9] J. H. Jeon and S. Y. Lee, Trend and Prospect of the Web 2.0 Technology, ETRI Technology Trends Analysis, Vol. 21, No. 5, pp. 141-153, October 2006.

[10] Josh Pasek, Eian More, and Daniel Romer, Realizing the Social Internet? Online Social Networking Meets Offline Civic Engagement, Journal of Information Technology \& Politics, 6, pp. 197215, 2009 http://dx.doi.org/10.1080/19331680902996403

[11] Krissi Danielson, Distinguishing Cloud Computing from Utility Computing, SaaS Week, March 26, 2008, URL= http://www.ebizq.net/blogs/saasweek/2008/03/distinguishing_clou d computing/

[12] Matthew Buckland, Future Web Trends, Innovation Series 2007 with Jimmy Wales, GM: New Media, M\&G Online, 2007.

[13] Next Generation Web Application SaaS (Software as a Service), NIDA (National Internet Development Agency of Korea), ISSUE ABC, pp. 1-4.

[14] Next Generation Web, Digital Contents/ Software Areas, ICT Standardization Roadmap 2009, TTA, pp. 1-75.

[15] Nokia's Mobile Web Technologies Overview, URL $=$ http://www.forum.nokia.com

[16] O. G. Min, H. Y. Kim, and G. H. Nam, Trends in Technology of Cloud Computing, ETRI Technology Trends Analysis, Vol. 24, No. 4, pp. 1-13, August 2009.

[17] PalmWebOS.org, URL = http://palmwebos.org/about/

[18] Read Write Web, URL = http://www.readwriteweb.com/archives/ the real-time web a primer part 1.php

[19] Read Write Web, URL = http://www.readwriteweb.com/archives/ top 5 web trends of 2009 the real-time web.php

[20] Residential technology, URL $=$ http://www.residentialtechnology services.com/default.asp

[21] S.Y. Lee, "Future web standardization technologies," ETRI, W3C Korea Office, pp. 1-96.

[22] S.Y. Lee, Web standardization present and future, TTA Journal, No. 105 , pp. 12-18.

[23] W3C, URL=http://www.w3.org/.

[24] Web strategy by Geremiah Owyang, URL $=$ http://www.webstrategist.com/blog/2009/04/27/future-of-the-social-web/

[25] World Wide Web Consortium MWI, URL= http://mobiforge.com/book/mobile-web-standards

[26] World Wide Web, URL=http://en.wikipedia.org/wiki/WWW.

\section{AUTHORS}

Young B. Choi is with Regent University, Virginia Beach, USA.

Young Han Choi is with ITU-T, Geneva, Switzerland.

Tae H. Oh is with Rochester Institute of Technology, Rochester, USA.

This article is an extended and modified version of a paper presented at the 2011 Interdisciplinary Conference of AHLiST, held May 20-22, 2011, at College of Technology, University of Houston, TX, USA. Submitted 15 June 2013. Published as re-submitted by the authors 08 November 2013 